\title{
An Audit of Appendectomies with Histopathological Correlations in A Single Centre
}

\author{
Authors \\ Sapna $\mathrm{M}^{1}$, Navya $\mathrm{N} \mathrm{O}^{2}$, Magdalene $\mathrm{K} \mathrm{F}^{3}$, Sumangala $\mathrm{B}^{4}$ \\ ${ }^{1}$ Assistant Professor Pathology, Sree Narayana Institute of Medical Sciences Chalaka, Ernakulam \\ Kerala.683594.India \\ Email: drsapnablore@yahoo.com Ph: 9633420919 \\ ${ }^{2}$ Assistant Professor Pathology, Sree Narayana Institute of Medical Sciences Chalaka, Ernakulam \\ Kerala.683594.India \\ Email: navyanarayano@gmail.com Ph: 8137985515 \\ ${ }^{3}$ Professor Pathology, Sree Narayana Institute of Medical Sciences, Chalaka Ernakulam Kerala.683594 \\ Email: magdalenekf@gmail.com Ph: 94963731923 \\ ${ }^{4}$ Professor and Head Pathology, Sree Narayana Institute of Medical Sciences Chalaka, Ernakulam \\ Kerala.683594 \\ Email: bsumangala2002@gmail.com Ph: 9495315759 \\ Corresponding Author

\section{Sapna M} \\ Assistant Professor Pathology, Sree Narayana Institute of Medical Sciences Chalaka, Ernakulam \\ Kerala.683594 India \\ Email: drsapnablore@yahoo.com.9633420919

\begin{abstract}
Appendicitis is one of the most common acute surgical conditions of the abdomen and an appendectomy is one of the most frequently performed operations worldwide. This is a retrospective analytical study during the period of October 2013 to October 2015. Overall 260 appendectomies were performed during the study period. 211 (81.1\%) had histopathological findings consistent with appendicitis, which was variously reported as acute suppurative appendicitis, transmural inflammation of the appendix with or without fecolith and gangrenous perforated appendix. Nine cases of fibrous obliteration of the lumen without evidence of inflammation were reported. Two cases showed parasite infection of Enterobius Vermicularis, one Chron s disease, one with tuberculosis and one with metastatic deposit of adenocarcinoma from stomach. The negative appendectomy rate was $9.6 \%$, the female sex accounted for $60 \%$ of the negative appendectomies

Key words: appendicitis, negative appendectomy rate
\end{abstract}




\section{Introduction}

Appendicitis is one of the most common acute surgical conditions of the abdomen and an appendectomy is one of the most frequently performed operations worldwide 1,2. Delayed diagnosis of appendicitis could lead to complication like perforation of appendix, peritonitis, sepsis, increased morbidity and mortality ${ }^{3,4}$. Clinical studies may determine best practice in the management of acute appendicitis. The knowledge about the clinical profile of appendicitis is an important mile stone in public health ${ }^{5,6}$. The lifetime risk of appendicitis has been estimated at $7 \%$ with peak incidence occurring between 10 and 30 years of age. The incidence of appendicitis varies in different population in different regions over time. The changing incidence has been attributed to a variety of environmental and behavioral factors that include general hygiene, parasite infection, enteric infection resulting in gastrointestinal lymphoid hyperplasia and variation in consumption of dietary fiber, but the definitive causes of appendicitis remain poorly understood 7 . Appendectomies are routinely performed in our institution and hence an audit to study, histopathological and clinical correlation was performed.

\section{Methods}

This is a retrospective analytical study during the period of October 2013 to October 2015.we used routine abstracts of hospital inpatient records to study the demographic and temporal profiles of emergency appendectomy for acute appendicitis and appendectomy in other circumstances. The study populations with histological reports of appendicitis were retrieved from the computer records. Negative appendectomy was defined as a post operative appendix specimen for suspected appendicitis that was however microscopically normal on histopathological examination without evidence of inflammation, tumor and parasite infestation 8-11. Analysis of the data was carried out by IBM SPSS version 20 .

\section{Results}

Overall 260 appendectomies were performed during the study period. The mean age of the patients was 35 years (5-75 years). Adults (>16 years) represent $77 \%$ and children $23 \%$ of the study population. The female sex accounted $(66.5 \%)$ and males $(33.5 \%)$

\section{Histopathological findings:}

Of the 260 resected appendix, 211 (81.1\%) had histopathological findings consistent with appendicitis, which was variously reported as acute suppurative appendicitis, transmural inflammation of the appendix (figure 1) with or without fecolith and gangrenous perforated appendix (figure 2). Nine cases of fibrous obliteration of the lumen without evidence of inflammation were reported. Two cases showed parasite infection of Enterobius Vermicularis, one Chron s disease, one with tuberculosis and one with metastatic deposit of adenocarcinoma from stomach. The histology findings are depicted in table 1 . The negative appendectomy rate was $9.6 \%$, the female sex accounted for $60 \%$ of the negative appendectomies.

Table 1: Histopathological diagnosis

\begin{tabular}{|l|l|}
\hline Histopathological diagnosis & No of cases \% \\
\hline Acute appendicitis & $156(60 \%)$ \\
Suppurative appendicitis with & $33(12.6 \%)$ \\
serosities & $18(6.9 \%)$ \\
Gangrenous appendicitis & $10(3.8 \%)$ \\
Lymphoid hyperplasia & $9(3.4 \%)$ \\
Fibrous obliteration & $4(1.5 \%)$ \\
Eosinophilic appendicitis & $2(0.7 \%)$ \\
Parasitic infestation & $1(0.3 \%)$ \\
Chrons disease & $1(0.3 \%)$ \\
Tubercular granuloma & $1(0.3 \%)$ \\
Adenocarcinoma metastatic deposit & $25(9.6 \%)$ \\
Normal histology & \\
& \\
& \\
\hline Total & \\
\hline
\end{tabular}




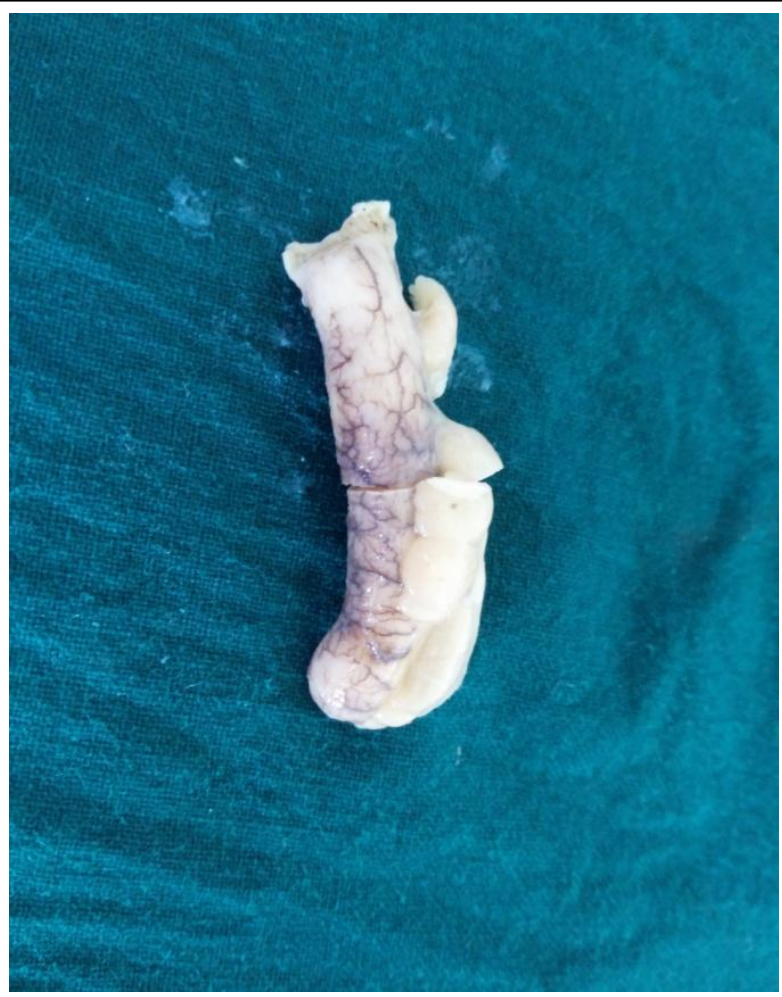

Figure 1: gross picture of appendix showing congested blood vessels

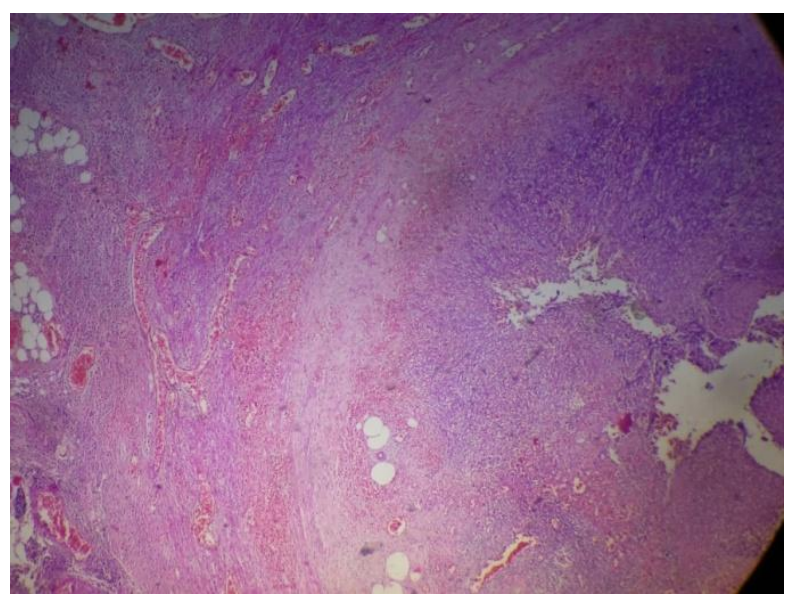

Figure 2: microscopy findings showing necrosis, hemorrhage of gangrenous appendicitis

\section{Discussion}

Appendectomy is a common surgical procedure for the management of acute appendicitis. The incidence of appendicitis varies substantially by country, geographical region, race, socioeconomic status, diet habits, hygiene, sex, age and season ${ }^{8}$. Study at south Korea done by Lee et al ${ }^{9}$ showed an overall incidence of appendicitis and appendectomy of 22.7 and 13.6 per 10,00 population per year, respectively which was found to be higher than that of western countries i.e 7.5 to 12 per 10,00 population per year. There is also significant morbidity and mortality associated with appendectomy. A diagnosis of appendicitis was most likely in patient with presence of pain, vomiting and fever. There is growing trend toward the sole use of antibiotics and avoidance of surgery altogether. Laporoscopic appendectomy has been ahead in the increasing consensus over the traditional open surgery. Abdominal ultrasonography is widely used for diagnosis of abdominal pathologies. It is also helpful in the evaluation of treatment. Obstruction of lumen is the dominant factor for appendicitis and fecoliths the usual cause of obstruction. Other causes of obstruction could be lymphoid hyperplasia, intestinal worms, tumors or other conditions ${ }^{10}$.

In this study, age of the patient ranged from 5 to 75 years, similar to other studies. In our study clinical diagnosis of acute appendicitis correlated with histopathology in $60 \%$ of cases. Gangrenous appendicitis was seen in $6.9 \%$ cases in our study which was similar to other studies ${ }^{3,11}$. Lymphoid hyperplasia was seen in $3.8 \%$ cases. In contrast, $16.1 \%$ cases of lymphoid hyperplasia was seen in a study done by Malloy et al ${ }^{12}$ has shown that lymphoid hyperplasia is frequently the precursor of acute appendicitis. Several studies have found luminal parasites in the appendix associated with or without appendicitis in the range of 0.3 to 3.1 $\%{ }^{13}$. Commonly found parasites are Enterobious Vermicularis and Schistosoma species. In our study , 2 cases of Enterobius Vermicularis parasitic infection were found. The frequency of eosinophilic appendicitis was $1.5 \%$ in our study which was closer to the incidence of other studies 2,14 . The negative rate of appendectomy varies from 15 to $30 \%{ }^{15}$.

Negative appendectomy rate was $9.6 \%$ which was within acceptable range of 10 to $20 \%$. Various studies have shown a wide range of rate that falls between 6.1 to $34.2 \%$ with higher values in females $^{2}$. The studies that evaluated the mortality and morbidity of incidental appendectomy associated with appendicitis were found to be insignificant ${ }^{16,17}$. 
Wang wt al ${ }^{17}$ demonstrated that TNF alpha and interleukin 2 expression are sensitive markers of inflammation in appendicitis.

\section{Conclusion}

Histopathological examination of appendectomy specimens helps to confirm the diagnosis of appendicitis and also unravels incidental pathologies. We can also know surgeons negative appendectomy rate.

\section{References}

1. Omiyale, Ayodeji Oluwarotimi, Samuel Adjepong. Histopathological Correlations of Appendectomies: A Clinical Audit of a Single Center. Ann Transl Med 2015; Jun; 3(9): 119

2. Shrestha R, Ranabhat SR, Tiwari M. Histopathologic analysis of appendectomy specimens. Journal of Pathology of Nepal 2012; mar 3: 215-219

3. Hale DA, Molloy M, Pearl RH, et al. Appendectomy: a contemporary appraisal. Ann Surg 1997;225:252-61.

4. Zoarets I, Poluksht N, Halevy A. Does selective use of computed tomography scan reduce the rate of "white" (negative) appendectomy? Isr Med Assoc J 2014;16:335-7.

5. Fitzmaurice GJ, McWilliams B, Hurreiz $\mathrm{H}$, Epanomeritakis E. Antibiotics versus appendectomy in the management of acute appendicitis: a review of the current evidence. Can J Surg 2011;54(5):307-314

6. Naveen K, Sareesh NN, Satheesha BN et al. Appendicitis and Appendectomy: A Retrospective survey in south Indian population. $\mathrm{J}$ of Surgical Academica 2013;3(2): 10-13

7. Al-Omran M, Mamdani M, McLeod RS. Epidemiologic features of acute appendicitis in Ontario, Canada. Can J Surg 2003; 46(4):263- 268.
8. Oguntola AS, Adeoti ML, Oyemolade TA. Appendicitis: Trends in incidence, age, sex, and seasonal variations in SouthWestern Nigeria. Ann Afr Med 2010;9:213-7.

9. Lee JH, Park YS, Choi JS. The epidemiology of appendicitis and appendectomy in South Korea: National Registry Data. J Epidemiol 2010;20:97105.

10. Subedi $\mathrm{N}$ et al. Acute appendicitis: a 2year review of clinical presentation and histopathology. Journal of Pathology of Nepal Oct 2011:104-107

11. Sanda RB, Zalloum M, El-Hossary M, Al Rashid F, Ahmed O, Awad A, Farouk A, Seliemt S, Mogazy K. Seasonal variation of appendicitis in northern Saudi Arabia. Ann Saudi Med 2008; 28(2):140-141

12. Malloy HR, Jason RS, Drew CR. The role of lymphoid hyperplasia in acute appendicitis. The Am J Surg 1945;67:81-6

13. Marudanayagam R, Williams GT, Rees BI.Review of the pathological results of 2660 appendicectomy specimens. J Gastroenterol 2006;41:745-9.

14. Park CS, Chang MS, Park IA, Kim YI, Choe G. Pathologic analysis of 2159 cases of appendix. Korean J Pathol 2000;34:3949

15. Kim Choy Ng, Shih Wei L. Clinical analysis of the related factors in acute appendicitis. Yale J bio med 200;75:41-5

16. Chang SKY, Chan P. Recurrent appendicitis as a cause of recurrent right iliac fossa pain. Singapore Med J 2004;45:6-8

17. Wang Y, Reen DJ, Puri P. Is a histologically normal appendix following emergency appendicectomy alway normal? Lancet 1996;20:1076-9. 